\title{
Choroid Plexus Carcinoma
}

National Cancer Institute

\section{Source}

National Cancer Institute. Choroid Plexus Carcinoma. NCI Thesaurus. Code C4715.

A malignant neoplasm arising from the choroid plexus. It shows anaplastic features and usually invades neighboring brain structures. Cerebrospinal fluid metastases are frequent. (Adapted from WHO) 